\title{
Examination of Stakeholders' Awareness and Preparedness for On-Line Learning in Ghana
}

\author{
Opoku, Osman Mustapha
}

Faculty of Economics and Business Administration, yawosman2004@yahoo.co.uk

Kuranchie, Alfred

Faculty of Education, Kuranchiealf@yahoo.com

Doi:10.5901/mjss.2015.v6n6p469

\begin{abstract}
The advent of Information Technology (IT) has broadened and widened education delivery in most countries of the world. Consequently, some countries are using IT to deliver education to people online. Unfortunately, however, on-line learning has not been widely instituted at all levels of education in Ghana. Certainly, before the educational institutions in the country can embark on such an endeavour, the concerns of stakeholders who have vested interest in on-line learning ought to be ascertained and addressed appropriately. This is necessary because the success of running an education programme such as on-line learning programme is dependent, to a large measure, on the extent to which it satisfies the whims and caprices of its stakeholders. Against this backdrop, the study was conducted to ascertain the awareness, concerns and preparedness of stakeholders for on-line education programmes. The study used questionnaire as a data collection tool. The empirical data were collected from stakeholders of tertiary education. The study has unraveled respondents' high level acceptance of on-line learning and indication of financial preparedness for on-line learning. The study has also unveiled that stakeholders' level of awareness of on-line learning is good, yet they have some concerns that need to be addressed to engender high patronage when it is widely introduced in the country. It is recommended that seminars, conferences and workshops be intensified to improve stakeholders' awareness on on-line learning.
\end{abstract}

Keywords: on-line learning, awareness, concerns, preparedness and willingness of on-line learning

\section{Introduction}

The mode of delivery of education has not been one way since its introduction centuries ago. Besides the traditional faceto-face education, other forms of distance education have been relied on to deliver valuable knowledge and skills to recipients in varied fields. Not too long ago, on-line learning emerged as another means to deliver education to people to improve their human capital development. On-line learning is conceived of as any form of instruction delivered through computer network (Cannon-Bowers \& Salas, 2001). With this mode of delivering education, learners may not come in contact with the instructor(s) during the period of education. Schank (2001) posits that on-line learning refers to instruction delivered over the internet or intranet.

Evidently, the concept of on-line learning is used interchangeably with e-learning by some authors. Adrich (2004) defines e-learning as a broader combination of processes, content, and infrastructure to use computers and networks to boost learning, management and delivery, to a large extent. Rosenberg (2001) also regards e-learning as the use of the Internet, web and the various corporate intranets to develop and deliver educational instructions to enhance knowledge and performance. In all the definitions, the role of internet is indispensable as without it on-line learning cannot be feasible.

Broadbent (2002) identifies four basic types of on-learning, namely, informal, self-pace, leader-led and performance support tools, which can be used individually and blended. With the informal learning, no instructor is involved and the learners seek for educational instructions independently. Self-pace learning is where modules are provided in electronic form and learners access them at their own pace. For the leader-led learning, instructions are provided by instructors in either asynchronously or synchronously. With synchronous, learners access learning materials in real time while in asynchronous, instructional materials are delayed. The fourth and the last type of on-line learning is through the use of performance support tools which refers to materials that learners can use to help perform a task (normally in software) such as using a wizard (Broadbent, 2002).

A variant of on-line learning is blended learning, which is the use of more than one mode of delivering a learning 
programme such as face-to-face education with on-line instruction. Garrison and Vaughan (2008) assert that blended learning is the "organic integration of thoughtful selected and complementary face-to-face and on-line approaches and technologies", p18. With blended learning, students enjoy classroom experience where there is physical interaction between instructors and students, and instruction delivered via technology only. So on-line learning could be neatly categorised into full on-line learning and blended learning.

According to Jones (1997), on-line learning is being adopted to be an alternative or complimentary to normal mode of education delivery worldwide. Instructively, the on-line learning models of higher education emanate from conventional distance education, which was initially introduced to enable people in remote, rural and hard to reach areas to gain access to higher education (Wagner, Hassanein \& Head, 2006). Technological advancement has been the major inspiration and driver for distance learning, which started with the integration of radio broadcast in the 1920's (Huynh, Umesh \& Valachich, 2003).

The growth of on-line learning has brought in its wake a new chapter in distance education and expansion of educational opportunities to reach people at different locations thereby affording them access to education (Chase, 1997). In more recent times, the advent of the internet has brought about unimaginable innovation in the provision and delivery of education at the tertiary level of education (Gunasekaran, McNeil \& Shaul, 2002, Teo \& Gay, 2006). Advance courses are being delivered via the internet to millions of people in different parts of the globe, which are benefiting varied groups of people. It needs to be noted that on-line learning is not employed only by institutions running and for distance education programmes but also by and for regular education programmes.

Many factors may account for on-line learning in any jurisdiction. According to Davis' Technology Acceptance Model, one of the factors that influence technology to be accepted is the perceived usefulness or benefits to be derived from such technology (Averweg, 2008). Like all rational buyers, for people to decide to adopt technology for any purpose, they would do cost and benefit analysis. They would critically analyse the likely benefits that would be derived from it. Parents and students would invest in on-line learning only when they have satisfied themselves that after pursuing the programme employers would willingly and readily accept the certificate that would be awarded. Loudon and Traver (2002) identify ubiquity, global reach, interactivity, information density and personalized/customization as special features and benefits of e-commerce and on-line learning. By ubiquity, it is available everywhere at all times. On-line learning liberates the educational environment from being restricted to a physical place and makes it possible to learn from one's desktop at home, at office or even from a vehicle, using mobile phones and other gadgets. Global reach as a benefit of on-line learning creates educational setting that goes beyond cultural and local boundaries for more expedient and cost effectiveness. Interactivity means allowing for two-way communication between the instructor and the students, while information density is the total amount and quality of information available to all partakers of the programme. Lastly, personalization feature of on-line learning allows tutors to modify their instructional materials to specific learners by finetuning the message to learners' needs, interest, and ability.

On-line learning also offers students, who may not want to go to traditional brick and mortar schools due to severe medical reasons, work schedule, domestic duties, fear of attacks and other violence, the chance to receive education anywhere. On-line learning environment, therefore, is not limited by location, income group, age or class size as it is in the brick and mortar school situation.

Wagner, Hassanein and Head (2006) posit that with the affordances provided by on-line learning to enable people to have higher education, institutions which offer both distance and regular education programmes need to run on-line programmes. In this regard, higher educational institutions would be able to expand their offerings to include on-line learning courses to compete with the growing numbers of virtual higher education institutions (Huynh, Umesh \& Valachich, 2003). It is about time all higher educational institutions all over the globe regarded on-line learning as a potent means to remain competitive and maintain their market share of tertiary education.

\subsection{Problem Statement}

The mode of delivery of instructions at various levels of education is going through a transformation. While some educational institutions have moved away from the traditional classroom delivery to on-line learning, some combine faceto-face learning with on-line learning otherwise termed as blended learning. Tertiary institutions are re-examining the way and manner they deliver both regular and distance education programmes to their clienteles. On-line learning is helping to create opportunities for educational institutions to offer cutting-edge education programmes for their students. More students are developing a desire and likeness for on-line education. According to Allen and Seaman (2008), on-line enrolments have been growing up appreciably overtaking that of higher education enrolment in general. The authors report that in the United States over 3.5 million college students took at least one on-line course in the fall term of 2006. 
This has been fueled by the fact that in the recent times, many more people are gaining access to the internet, the cost of computers are decreasing and general computer literacy is increasing (Huynh et al, 2003).

UNESCO (2007) observed that most institutions within sub-Saharan Africa were finding ways to explore the possibility of using on-line learning to address the high demand for higher education. Ghana is no exception and in addition service providers in the country are providing broadband services, wireless technology services and modems that allow users to access internet anytime and anywhere. The improvement in technology in the country has created opportunities for higher educational institutions to deliver their educational contents to students 24/7.

Nonetheless, before introduction of such mode of delivery of education in the country, that is on-line learning, major stakeholders' concerns need to be sought in order to recommend solutions to address them. Are authorities prepared for on-line learning programmes, are employers ready to accept graduates of on-line learning programme, do students and parents have confidence in on-line learning, and are tertiary institutions prepared to run on-line education programmes? These and many other questions regarding on-line learning begged for answers. The study sought to find answers to the questions.

\subsection{Study Objectives}

The general aim of the study was to ascertain the acceptability of on-line learning programmes in the country. Specifically, the study sought to investigate stakeholders' awareness, concerns and preparedness for on-line learning.

\section{Methodology}

This section of the write-up deals with the approaches that were used to conduct the survey. It covers the design, population, data collection method and data analysis plan.

\subsection{Design}

The study used both explorative and descriptive survey. Polit and Hunglar (1996) describe research design as an overall plan for gathering and analysing data including measures to enhance both internal and external validity. Survey was deemed appropriate for this study in that it enabled the researchers to sample views and ideas of large number of respondents on the issue under study. The research subjects also had the opportunity to express their independent views on the issues. The quantitative study made it possible to gather data from major stakeholders of tertiary education on their awareness, concerns and preparedness for on-line education.

\subsection{Population and Sampling}

The population of the study comprised major stakeholders of on-line learning in the context of tertiary education in Ghana such as authorities of educational institutions, lecturers, students and employers. Purposive and simple random techniques were used to select representatives of the larger population.

\subsection{Data Collection Methods and Analysis}

The questionnaire was employed to gather data from the research subjects. Both open and close ended questions were crafted on the instrument to elicit appropriate responses. The instrument was validated through peer-review. Data processing and analysis were made possible by the use of SPSS version 16.

\section{Presentation of Results}

\subsection{Bio-data of Respondents}

Table 1: Gender Distribution of Student-respondents

\begin{tabular}{lcc}
\hline Gender & Freq. & Percent (\%) \\
\hline Male & 66 & 57.4 \\
Female & 49 & 42.6 \\
\hline Total & 115 & 100.0 \\
\hline
\end{tabular}


The gender distribution of students shows that more males than females participated in the study. The males dominating in the study reflects the general situation in the higher educational institutions in the country, where male students outnumber their females counterparts. In Ghana, female students' numbers at the lower levels of education are high but as they move up the education ladder the numbers dwindle as opposed to their male counterparts, whose numbers tend to remain stable through the higher levels of education.

Table 2: Educational Status of Student-respondents

\begin{tabular}{lcc}
\hline Status & Freq. & Percent (\%) \\
\hline Diploma/HND students & 77 & 67 \\
Undergraduate students & 38 & 33 \\
\hline Total & 115 & 100 \\
\hline
\end{tabular}

The results in Table 2 show that more Diploma/Higher National Diploma (HND) students than undergraduate students took part in the study. The study sought to ascertain the extent to which Polytechnic and University students have good knowledge on on-line learning and how prepared they are to enrol in academic programmes delivered on on-line basis for advance degrees. After HND and degree programmes, the students who wield the intellectual wit and energy, interest and financial muscles pursue further studies in their various fields to improve their human capital for the job market and the social world. In the knowledge-based economies, students' desire to have advance studies is unquenchable so they undertake various forms of education, which in the contemporary times include on-line learning. Undoubtedly, without good knowledge about on-line learning, students and other stakeholders may not be able to take a cogent decision on enroling in any educational programmes that are delivered on line.

\subsection{Awareness of On-line Learning}

Questions were raised to seek respondents' awareness of on-line learning and the responses are presented in Table 3.

Table 3: Respondents' awareness of on-line courses

\begin{tabular}{lcccc}
\hline Response & $\begin{array}{c}\text { Students } \\
\text { Freq.(Percent) }\end{array}$ & $\begin{array}{c}\text { Staff } \\
\text { Freq.(Percent) }\end{array}$ & $\begin{array}{c}\text { Administrators } \\
\text { Freq.(Percent) }\end{array}$ & $\begin{array}{c}\text { Employers } \\
\text { Freq.(Percent) }\end{array}$ \\
\hline Yes & $105(91.3 \%)$ & $18(100 \%)$ & $19(100)$ & $8(100)$ \\
No & $10(8.7 \%)$ & $0(0)$ & $0(0)$ & $0(0)$ \\
\hline Total & $115(100)$ & $18(100)$ & $19(100)$ & $\mathbf{8}(100)$ \\
\hline
\end{tabular}

Inquiring about stakeholders' awareness of on-line learning is relevant since without that they cannot accept or reject online education programmes. The results depict that a disproportionate chunk of the participants are very much aware of on-line learning. Over $90 \%$ of the students and all the staff, administrators and employers who participated in the study indicated that they are very much aware of learning programmes delivered on line. In this time and age when the internet and other media provide information on education, it is not astonishing to discover that students of tertiary institutions and other stakeholders of tertiary education are pretty much aware of on-line learning and its variants. Various media platforms in the country have innumerable information on on-line learning purported to notify potential participants of it. Both electronic and print media have started putting up other information on on-line learning, which should inform the average elite of it.

A fellow-up question was posed to determine the respondents' level of awareness of on-line learning. The answers obtained are shown in Table 4.

Table 4: Respondents' Level of Awareness of on-line learning

\begin{tabular}{lcccc}
\hline Response & $\begin{array}{c}\text { Students } \\
\text { Freq./percent }\end{array}$ & $\begin{array}{c}\text { Staff } \\
\text { Freq.(Percent) }\end{array}$ & $\begin{array}{c}\text { Administrators } \\
\text { Freq.(Percent) }\end{array}$ & $\begin{array}{c}\text { Employers } \\
\text { Freq.(Percent) }\end{array}$ \\
\hline Low & $30(26.1)$ & $0(0)$ & $1(5.3)$ & $1(12.5)$ \\
Moderate & $71(61.7)$ & $12(66.7)$ & $11(57.9)$ & $4(50)$ \\
High & $14(12.2)$ & $6(33,3)$ & $7(36.8)$ & $3(37.5)$ \\
\hline Total & $115(100)$ & $18(100)$ & $19(100)$ & $8(100)$ \\
\hline
\end{tabular}


The results demonstrate that the majority of the respondents' level of awareness is moderate. It is barely one-third of the students, staff, administrators and employers' level of awareness is high. Implicitly, although the majority of the respondents are well aware of this mode of delivering education, they may lack information on the nitty-gritty of it as their level of awareness is not high. The information they have about on-line learning is not sufficient to convince students and parents to patronize it and employers and administrators may be unwilling to employ job applicants who possess certificates earned from on-line learning education programmes.

Respondents' major sources of awareness of on-line learning were sought. The respondents who were pretty much aware of on-line learning were asked to indicate how they got information about it. The responses to that effect are presented in Table 5.

Table 5: Respondents' Sources of awareness on on-line learning

\begin{tabular}{lcccc}
\hline Response & $\begin{array}{c}\text { Students } \\
\text { Freq./Percent }\end{array}$ & $\begin{array}{c}\text { Staff } \\
\text { Freq.(Percent) }\end{array}$ & $\begin{array}{c}\text { Administrators } \\
\text { Freq.(Percent) }\end{array}$ & $\begin{array}{c}\text { Employers } \\
\text { Freq.(Percent) }\end{array}$ \\
\hline Lectures & $15(14.3)$ & $4(22.2)$ & $2(10.5)$ & $0(0)$ \\
Seminar/Conference/Workshop & $8(7.6)$ & $3(16.7)$ & $5(26.3)$ & $1(12.5)$ \\
Print and electronic media & $52(49.5)$ & $8(44.4)$ & $10(52.6)$ & $5(62.5)$ \\
Colleagues & $12(11.4)$ & $3(16.7)$ & $1(5.3)$ & $0(0)$ \\
Others & $18(17.3)$ & $0(0)$ & $1(5.3)$ & $2(25)$ \\
\hline Total & $105(100)$ & $\mathbf{1 8 ( 1 0 0 )}$ & $\mathbf{1 9 ( 1 0 0 )}$ & $\mathbf{8 ( 1 0 0 )}$ \\
\hline
\end{tabular}

The results as presented in Table 5 portray that the majority of the respondents' major source of information on on-line learning is the media. The advertisements and education programmes run on the various print and electronic media provided them information on on-line learning. Institutions and individuals who are interested in running on-line learning programmes have not seriously organised seminars, conferences and workshops on it for students and other stakeholders to create more awareness on it. Such events are very effective means to give people in-depth information about new endeavours. Participants would be afforded the opportunity to seek clarifications and ask pertinent questions about it.

The majority of the respondents' low level of awareness of on-line learning may be attributable to their source of information on it. Arguably, information on an education programme obtained from the media may not be comprehensive and adequate. It may be difficult for radio, television stations and the rest to give adequate information on on-line learning programmes and for listeners to seek clarification on issues that bother on this mode of education delivery.

\subsection{Perception of On-line learning}

The respondents were requested to indicate their perception on on-line learning. The respondents overwhelmingly showed positive perception of on-line learning. The student-respondents indicated that on-line learning saves time, it is flexible or it provides a flexible platform of learning, learners learn at the comfort of their homes, patronisers acquire knowledge irrespective of geographical location, it is fast, convenient and stress free.

The staff-respondents also intimated that on-line learning is done anytime and anywhere and that distance is not a barrier. On-line learning saves time and travel expenses, it is convenient as learners sit at the comfort of their homes to enjoy learning, and it is possible to access information for a course.

Further, the employer-respondents were of the view that on-line learning is convenient and it is not stressful, while the Administrators were of the opinion that on-line learning provides access to education irrespective of location, it is convenient, and it encourages broad knowledge sharing and experiences.

\subsection{Concerns of On-line learning}

Notwithstanding the positive perception that the majority of the respondents have about on-line learning, the following concerns were raised about it. The student-respondents averred that on-line learning may be difficult for learners to pose questions and get immediate feedback from lecturers unlike the face to face situation, there is lack of interaction between learners and staff, it may be uneasy to get explanations of difficult issues or topics, there is unstable network system, the issue of credibility of the institutions organising the programme hence it can be fraudulent. The other concerns raised by the student-respondents include the fact that employers may not accept certificates earned from on-line learning, 
assessment of student learning may be ineffective, it may be time consuming and could be abused by some people. The rest of the concerns are that on-line learning is very costly, there is lack of supervision of student work and it is not appropriate for skilled-based courses as it cannot provide some skills to students to become competent in their areas of specialisation.

The staff respondents' concerns on on-line learning are that it is not possible to supervise learning students' activities and exercises, it is costly, there is lack of interaction between learners and lecturers, internet connectivity may be a problem, information may not be secured, accessibility may be a problem, it is expensive and there is proliferation of institutions, which claim to be offering it.

The employers were concerned about the fact that on-line learning is expensive, fake certificate may be awarded, there is doubt of genuineness of student work as there is lack of supervision of student learning, internet connectivity and power problems, lack of inter-personal interaction and socialisation of students.

The administrators' concerns of on-line learning include the fact that there could be impersonation, there is lack of supervision of student exercises, it is costly, internet connectivity and technical problems are eminent and it is stressful and time constraint.

The concerns raised by the participants boarder on the effectiveness of student learning and assessment, cost of the programme, genuineness of institutions that run the programmes and the certificates awarded and economic issues like power supply and internet connectivity.

\subsection{Preparedness for On-line Learning}

The study sought to ascertain the preparedness of respondents for on-line learning programmes. The preparedness was viewed from three perspectives: financial, competence and other resources.

Table 6: Student-respondents' Financial Readiness for On-line Learning

\begin{tabular}{ccc}
\hline Response & Freq. & Percent (\%) \\
\hline Yes & 76 & 66.1 \\
No & 39 & 33.9 \\
\hline Total & 115 & 100 \\
\hline
\end{tabular}

The results portray that more than two-thirds of the respondents indicated that they have the financial capacity to pursue on-line learning. It is barely one-third of them who indicated that they do not have the financial strength to pursue on-line education programme, leading to the award of degrees. The results mean that the students' financial capability to pursue on-line education programme is not in doubt, although earlier they had indicated that programmes run on-line are costly.

The student and staff-respondents were asked to rate their level of technical competence in undertaking on-line learning. This stems from the fact that e-learning requires different sets of skills to enable learners to be successful with it (Romiszowski, 2004). Jones (2003) notes that e-learning requires technical sophistication of both instructors and learners involved it. The technical competence includes ability to use computer for on-line services and to take part in learning exercises delivered on-line either synchronously or asynchronously or both. Basically, on-line learning involves video conferencing, forum discussions, receiving and submitting assignments on-line and chatting, which all demand very good knowledge and acumen in the use of computer.

Table 7: Respondents' Level of Competence in ICT

\begin{tabular}{lcccc}
\hline & Students & & \multicolumn{2}{c}{ Staff } \\
\hline Response & Freq. & Percent (\%) & Freq. & Percent (\%) \\
\hline Low & 23 & 20 & 2 & 11.1 \\
Moderate & 60 & 53.2 & 11 & 61.2 \\
High & 32 & 26.8 & 5 & 27.7 \\
\hline Total & 115 & 100 & 18 & 100 \\
\hline
\end{tabular}

The results show that most of the respondents rated their ICT competence moderately; fairly over a quarter of them rated their competence high. The results imply that majority of the student-respondents do not possess the technical competence to undertake on-line learning courses. Per the demand of on-line learning, prospective students need to 
amass an enviable knowledge and skills in ICT to be able to fruitfully embark on such a programme. It is deduced from the results that both students and staff doth not possess enviable technical acumen to embark on on-line education. However, the staff who would be handling the courses also need to be highly competent in ICT so that when their institutions commence on-line learning programmes they can be alive with their responsibilities. The lecturers' work in online learning includes preparation of models and materials, giving and marking assignments, which they need very good knowledge and skills to do it.

Table 8: Other Resources to pursue On-line Learning

\begin{tabular}{ccc}
\hline Response & Freq. & Percent (\%) \\
\hline Yes & 60 & 52.2 \\
No & 55 & 47.2 \\
\hline Total & 115 & 100
\end{tabular}

Although the results show that majority of the student-respondents think they have other resources to undertake on-line learning, the difference between them and those who do not have the capacity to enrol in it is not wide. The study sought to ascertain other resources such as computers and their accessories, and internet accessibility that learners need to be able to embark on on-line learning. Over 47 percent of the respondents indicated that they do not possess other resources that are needed to undertake on-line learning.

The results thus far show that the respondents' willingness to pursue on-line learning is very encouraging. Consequently, the respondents were asked to indicate the type of on-line learning they prefer. The results are presented in the table below.

Table 9: Respondents' Preferred On-line Learning

\begin{tabular}{lcccc}
\hline Response & $\begin{array}{c}\text { Students } \\
\text { Freq.(Percent) }\end{array}$ & $\begin{array}{c}\text { Staff } \\
\text { Freq.(Percent) }\end{array}$ & $\begin{array}{c}\text { Administrators } \\
\text { Freq.(Percent) }\end{array}$ & $\begin{array}{c}\text { Employers } \\
\text { Freq.(Percent) }\end{array}$ \\
\hline Full on-line & $66(57.4)$ & $1(5.6)$ & $2(10.5)$ & $2(25)$ \\
Blended on-line & $49(42.6)$ & $17(94.4)$ & $17(89.5)$ & $6(75)$ \\
\hline Total & $115(100)$ & $18(100)$ & $19(100)$ & $\mathbf{8 ( 1 0 0 )}$ \\
\hline
\end{tabular}

The results clearly demonstrate that while the majority of the student-respondents prefer on-line to blended learning, overwhelming majority of the staff, administrators and employers prefer blended learning to full on-line learning. With the full on-line learning, the students do not come in contact with the instructors so everything is done via the internet. country.

The following suggestions were given by the respondents to make on-line learning effective and acceptable in the

Information Communication and Technology education should be vigorously pursued at the Junior and Senior High School levels, more computers and their accessories be made available to school, there is the need to improve accessibility of internet services in the country, seminars on on-line learning for tertiary students need to be taken vigorously, moderate fees should be charged, intensify publicity on on-line learning, there should scholarships and subsidies for students and reliable internet services.

\section{Conclusion}

The advent and revolution of Information and Communication Technologies have engendered the integration of Technology tools in education. ICT has changed the landscape of delivering education in most economies. In a country like Ghana where on-line learning is being experienced, the study sought to elicit concerns of prospective students of online learning. The study has brought to light that most students, staff, administrators and employers have positive perception about on-line learning as they deem it more convenient and flexible. Nonetheless, the participants have concerns for credibility of institutions running such programmes, lack of supervision of students' learning and assessment, lack of interaction between staff and students and poor internet facilities. It is prudent for educational institutions intending to offer on-line education programmes to use platforms like conferences, seminars, workshops and others to adequately educate citizens on on-line mode of delivering education to provide adequate information on it. 


\section{References}

Adrich, C. (2004). Simulations and Future of Learning. San Francisco, California: Jossey-Bass Pfeiffer.

Allen, E. and Seaman, J. (2008). On-line nation: Five years of growth in on-line learning. The Sloon Consortium.

Averweg, R. U. (2008). Information Technology Acceptance in South Africa: An Investigation of Perceived Usefulness,Perceived Ease of Use, and Actual System Use Constructs. The African Journal of Information Systems, , 1 (1), 4 - 6.

Broadbent, B. (2002). ABCs of e-learning: Reaping the benefits and avoiding the pitfalls. San Francisco, California: Jossey-Bass Pfeiffer. Cannon-Bowers, J. A. and Salas, F. (2001). Reflections on shared cognition. Journal of Organisational Behaviour, 22(2), 195-210.

Chase, N. (1997). Raise your training ROI. http//qualitymag.com21/01/2013.

Garrison, D. R. and Vaughan, N. (2008). Blended learning in higher education. San Francisco, California: Jossey-Bass.

Gunasekara, A. McNeil, R. D. and Shaul, D. (2002). E-learning research and applications. http://www.hezel.com/global report.

Huynh, M. Q., Umesh, U. N. and Valachich, J. (2003). E-learning as an emerging entrepreneurial Enterprise in universities and firms. Communications of the AIS, 12, 48-68.

Jones, A. J. (2003). ICT and future teachers: Are we preparing for e-learning? Paper presented at the IFIP Working Groups 3.1 and 3.3 Conference: ICT and the teacher of the future. January 27-31, 2003. Melbourne, Autralia.

Jones, G. R. C. (1997). Cyber schools. Englewood, CO: Jones Digital Century.

Loudon, K. C. and Traver, C. G. (2002). E-commerce. New York: Pearson Education Inc.

Polit, D. E. and Hunglar, B. P. (1998). Nursing research: Principles and methods (5 $5^{\text {th }}$ ed.). Pennsylvania: J. B. Lippincott. Co.

Rosenberg, M. J. (2001). E-learning: Strategies for delivering knowledge in the digital age. New York, McGraw-Hill.

Romiszowski, A. (2004). How's the e-learning baby? Factors leading to success or failure of the educational technology innovation. Educational Technology, 44(1), 5-27.

Rossett, A. and Sheldon, K. (2001). Beyond the podium: Delivering training and performance to a digital world. San Francisco, California: John Wiley and Sons.

Schank, R. C. (2001). Designing world class e-learning. New York: McGraw Hill Publication.

Teo, C. B. and Gay, R. K. L. (2006). A knowledge-driven model to personalized e-learning. ACM journal of Educational Resources in Computing, 6(1), 1-15.

UNESCO (2007). Dakar+7 Education for All in Africa. Dakar: UNESCO.

Wagner, N., Hassani, K and Head, M. (2008). Who is responsible for e-learning success in higher education: A stakeholder analysis. Educational Technology and Society, 11(3), 26-36. 